John Carroll University Carroll Collected

2019

\title{
Nominal Stock Price Anchors: A Global Phenomenon?
}

\author{
Kee-Hong Bae \\ York University \\ Utpal Bhattacharya \\ Hong Kong University of Science and Technology \\ Jisok Kang \\ john carroll, jkang@jcu.edu \\ S. Ghon Rhee \\ University of Hawaii, Manoa
}

Follow this and additional works at: https://collected.jcu.edu/fac_bib_2019

\section{Part of the Business Commons}

\section{Recommended Citation}

Bae, Kee-Hong; Bhattacharya, Utpal; Kang, Jisok; and Rhee, S. Ghon, "Nominal Stock Price Anchors: A Global Phenomenon?" (2019). 2019 Faculty Bibliography. 40.

https://collected.jcu.edu/fac_bib_2019/40 


\title{
Nominal stock price anchors: A global phenomenon?
}

\author{
Kee-Hong Bae, Utpal Bhattacharya , Jisok Kang, S. Ghon Rhee
}

\begin{abstract}
A B S T R A C T
Weld et al. (2009) find that the average nominal U.S. stock price has been approximately $\$ 25$ since the Great Depression. They report that this "nominal price fixation is primarily a U.S. or North American phenomenon." Using a larger data set from 38 countries, we show that this nominal price fixation is a global phenomenon. We exploit the introduction of the euro in 1999 to show that stock splits maintain these nominal stock price anchors. Generally, firms in countries with larger drops in nominal prices had fewer stock splits after stock prices were displayed in euros.
\end{abstract}

Anchoring is a cognitive bias that describes the common human tendency to rely excessively on the first piece of information offered (the "anchor") when making decisions. Tversky and Kahneman (1974) describe an experiment in which a group of students, given five seconds to evaluate the product of eight numbers, estimated that 1 X2X3X4X5X6X7X8 was 512 but $8 \times 7 \times 6 \times 5 \times 4 \times 3 \times 2 \times 1$ was 2250 . The first digit, the anchor, mattered. ${ }^{1}$

Anchors also matter in finance. In an intriguing paper, Weld et al. (2009) find that the average nominal price for a share of stock on the New York Stock Exchange (NYSE) and the American Stock Exchange (AMEX) has been approximately \$25 since the Great Depression. The price has not even kept pace with the rate of inflation. However, they find that 16 other countries did not share this peculiar trait. Hence, they conclude that the nominal price fixation is primarily a U.S. or North American phenomenon.

The goal of this paper is to revisit their last conclusion. Because anchoring is such a common human trait, we are skeptical that the United States is the only country whose stock markets exhibit this phenomenon. To find out whether the nominal 
price fixation is indeed a U.S. phenomenon, we extend the analysis by Weld et al. (2009) to international markets using a larger data set. We collect the nominal stock prices of firms, in both the local currency and the U.S. dollar, at the end of June in each year for 38 countries from 1981 to 2010.

Five interesting, sometimes, surprising facts stand out in this panel. The first four are suggestive and the fifth is our main formal test. First, when we compute the mean or median level of stock prices in a country over the sample period, we observe a large variation between countries. The mean (median) of the nominal price level in Switzerland, for example, is $\$ 925$ (\$348.9), whereas that of Hong Kong is only $\$ 0.6(\$ 0.1)$. The U.S. mean (median) share price is $\$ 51.3(\$ 21.9) .{ }^{2}$ It is clear that a global anchor does not exist.

Second, surprisingly, the median nominal stock price of all surviving firms in our sample remains remarkably flat and stable throughout the sample period, suggesting that nominal share prices are held roughly constant, although these firms generate positive returns on average. In fact, the median level of nominal stock prices in 2010 is remarkably similar to the median level of nominal stock prices 29 years earlier.

Third, a firm's nominal stock price has a tendency to revert to the stock price level that it had when it first entered the panel. When we partition our sample firms into tercile groups by their nominal stock price levels every year and keep track of the tercile group membership, we find that a majority of firms in almost all countries remains in their initial tercile group most of the time.

Fourth, Weld et al. (2009) show that the correlation between average nominal stock prices and the primary stock exchange index in their sample of 16 countries is the lowest and the next-to-lowest for the New York Stock Exchange and the Toronto Stock Exchange, respectively. They argue that the low correlations in the U.S. and Canada are suggestive of the fact that nominal price fixation is primarily a North American phenomenon. Our results for 38 countries show that most of them had lower correlations than the U.S. or Canada.

Fifth, and finally, we show that nominal stock prices tend to revert to their country-specific anchors due to corporate actions, such as stock splits and reverse stock splits. This is our main test. This test exploits the introduction of the euro in January 1,1999. Nominal stock prices in nine European Union members in our sample were converted to the euro using the fixed exchange rate set for each country on December 31,1998. There was a large variation in conversion rates. For instance, the conversion rate for the Italian lira was 1936.27 lira per euro, whereas the conversion rate for the German deutsche mark was 1.95583. Given these conversion rates, after the euro was introduced, countries like Italy had larger drops in nominal prices than countries like Germany. This implies that if stock splits (reverse stock splits) are used by corporations to decrease (increase) their nominal prices towards an anchor-a hypothesis that was first introduced by Dyl and Elliott (2006)-Italian firms should split a lot less than German firms (or perhaps even engage in more reverse-splits) after the introduction of the euro. We test this prediction and find consistent evidence.

We use the proportion of firms with stock splits and the proportion of firms with reverse stock splits around the introduction of the euro. We do not see a statistically significant change in the number of German firms doing stock splits after the introduction of the euro. In contrast, we see the number of Italian firms doing stock splits decreasing after the introduction of the euro. The statistical significance is strong. More generally, for the 9 euro countries that we have data on, if the conversion rate was $x$ local currency to 1 euro, the higher the $\mathrm{x}$, which means the higher the drop in nominal prices, the larger is the drop in stock splits. Reverse stock splits are rare occurrences. However, even here, we see an increase in the number of Italian firms doing reverse stock splits after the introduction of the euro. The change in reverse stock splits for the other countries are insignificant. This test gives us formal confirmatory evidence that firms indeed like to have fixed nominal anchors.

Our findings have links, directly and indirectly, with many studies. The direct link is with Weld et al. (2009), who find that firms proactively use corporate actions like stock splits to keep their prices within a narrow trading range. Why? They conclude that it must be norms and traditions. In our paper, we show that this phenomenon is global, and we therefore conclude that norms and traditions exist in all countries, not just in the U.S. Our paper also has a direct link to Dyl and Elliott (2006), who find that firms tailor their share prices around a specific range to reflect the desires of owners for an "anchor." George and Hwang (2004) observe that investors use the 52-week high as an "anchor" against which they value stocks. Baker et al. (2012) show that the 52-week high price is a reference point for valuing corporations in mergers and acquisitions.

Incidentally, anchoring exists not just in financial markets but also in many other markets. ${ }^{3}$ That leads to our last question. Why do firms use anchors? The anchoring literature in finance suggests that firms are catering to their investors because their investors use anchors. So our paper has important ramifications for the catering hypothesis (Baker et al., 2009) literature, as well as the investor recognition literature (Merton, 1987). A definite exploration of the question of why firms use anchors, however, is beyond the scope of this paper.

\footnotetext{
2 The mean nominal price of $\$ 51.3$ for U.S. stocks in our sample differs from the mean price of $\$ 25$ in Weld et al. (2009) for many reasons. Our sample covers only the stocks on NYSE from 1981 to 2010, whereas their sample covers all NYSE and AMEX stocks from 1933 to 2007. A more important difference is that they exclude Berkshire Hathaway from the sample, whereas we include it. The mean price drops to $\$ 26.2$ without Berkshire Hathaway in our sample.

${ }^{3}$ Flood and Mussa (1994) discuss how important inflation anchors are in generating price stability in monetary policy. Exchange rates serve as anchors (Edwards, 1992). Precedents in legal theory are nothing but anchors (e.g., Diamond et al., 2011). In labor economics, the concept of career anchors, first explored by Schein and Maanen (1990), is becoming a fruitful field of study. In marketing, it has been determined that the purchase decision and the sell decision use different anchors (see, Simonson and Drolet, 2004). In real estate, prior price discounts serve as anchors in the housing choice decision (Arbel et al., 2014).
} 
The rest of the paper proceeds as follows. In Section 1, we describe our data sources, sample construction, and summary statistics. In Section 2, we analyze the trends in nominal stock prices. In Section 3, we examine how the introduction of the euro exogenously affected nominal anchors and the consequent corporate actions undertaken to deal with this. We conclude in Section 4.

\section{Data}

\subsection{Nominal stock price}

We start with the 49 countries analyzed in La Porta et al. (2006). We drop the following nine countries that have fewer than 40 firms on average: Ecuador, Jordan, Kenya, Nigeria, Sri Lanka, Taiwan, Uruguay, Venezuela, and Zimbabwe. We also exclude Finland and Mexico because they have less than 10 yearly observations of nominal stock prices prior to their currency regime changes, on which we elaborate later. The remaining 38 countries have reasonably large stock markets. We collect nominal stock prices of firms listed on each country's main organized exchange, in both the local currency and the U.S. dollar, at the end of June in each year from 1981 to $2010 .{ }^{4}$ We define the main organized exchange in a country as the exchange that holds the largest total stock market capitalization of the listed firms in that country. For example, the New York Stock Exchange and the London Stock Exchange, respectively, are the main exchanges in the U.S. and the U.K. The nominal stock price data are obtained from Datastream. We require that our sample firms have at least 10 consecutive yearly observations of nominal stock prices and market capitalizations. This restriction results in a sample of 21,285 firms from the 38 countries.

The first four columns of Table 1 show the list of countries in the sample, the sample period in each country, the number of firms, and the name of the local currency. There is a large variation in the number of sample firms covered by Datastream across countries ranging from a minimum of 44 firms in Brazil to a maximum of 2816 firms in the U.S. For most countries, the sample period is 20-30 years. The last four columns of Table 1 present the mean and the median of the nominal stock prices at the end of June in each year in the local currency and in the U.S. dollar for each country during the sample period. We notice that the mean share price is much higher than the median share price in all countries. In quite a few cases, the mean price is several times higher than the median price, suggesting positively skewed distributions in nominal stock prices. An extreme case is Chile, where the mean price (3,813,682 pesos) is 13,620 times greater than the median price (280 pesos). We focus on the median prices in the analyses that follow because of this positive skewness.

The main takeaway from Table 1 is the observation that there is a large variation in nominal prices between countries. The mean (median) of the nominal price level in Switzerland, for example, is $\$ 925$ (\$348.9), whereas that of Hong Kong is only $\$ 0.6$ (\$0.1). The U.S. mean (median) share price is \$51.3 (\$21.9). It is clear that a global anchor does not exist.

We note that some of our sample countries have experienced regime changes with respect to their local currencies. For example, nine European countries in our sample adopted the euro in 1999. ${ }^{5}$ Turkey revalued its currency in 2005 as well. In the Datastream database, the nominal stock prices in a country before a regime change are denoted in the new currency after the regime change (i.e., the euro for all euro currency countries, and the new lira for Turkey). This implies that nominal stock prices before the regime change are converted by Datastream to new nominal stock prices using the conversion rate on the date of the regime change. For example, all local currency nominal prices in the euro area before January of 1999 were converted to and presented in euros using the fixed exchange rate set for each country on December 31, 1998. Similarly, the Turkish lira before January 1, 2005 was converted to and presented in the new currency using a fixed conversion rate set on December 31, 2004.

If anchors exist in nominal stock prices, currency regime changes are likely to have disrupted the existing anchors. For this reason, they offer us a natural experiment to observe what happens during the change. We exploit this insight in our main analysis.

\subsection{Other variables}

We collect from Datastream the total return index of each stock that captures the actual growth in the value of a share held over the previous year to the current year adjusted for all capital distributions, including cash dividends, stock splits, stock dividends, etc.

To examine stock split and reverse stock split activities of firms from the nine countries that adopted the euro in 1999 (we exclude Greece because it adopted the euro two years later), we obtain data from Capital IQ (CIQ) Key Development and RavenPack databases. These databases provide summaries of material news and events that may affect the market value of securities. We used two databases for cross-checking. The specific data we obtained were the dates of the stock split or the reverse stock split, and the corresponding split ratios. The split ratio for each firm in each year is greater than 1 (less than 1 ) \{equal to 0 \} if the firm splits (reverse splits) \{does not split\}. We require that the firms be present during the eight-year period from 1998 to 2005. The sample selection results in 1225 euro firms, with France representing the most firms (416) followed by Germany (314) and Italy (111).

\footnotetext{
${ }^{4}$ Some countries have more than one exchange with different listing rules. We focus on the main exchange so as to obtain one exchange per country.

${ }^{5}$ The number of euro countries in our sample becomes ten as Greece adopted the euro on January 1, 2001.
} 
Table 1

Mean and median of nominal stock prices per country. This table shows the mean and median of nominal stock prices in local currency at the end of June in each year from 1981 to 2010 per country. It also shows the mean and median of nominal stock prices in U.S. dollars at the end of June in each year from 1981 to 2010 per country. To be included in the sample, firms are required to have at least 10 consecutive yearly observations.

\begin{tabular}{|c|c|c|c|c|c|c|c|}
\hline \multirow[t]{2}{*}{ Country } & \multirow[t]{2}{*}{ Period } & \multirow[t]{2}{*}{ No. of firms } & \multicolumn{3}{|l|}{ Local currency } & \multicolumn{2}{|c|}{ U.S. dollars } \\
\hline & & & Name & Mean & Median & Mean & Median \\
\hline Argentina & $94-10$ & 80 & Argentine peso & 4.6 & 2.0 & 2.4 & 1.0 \\
\hline Australia & $81-10$ & 1154 & Australian dollar & 2.2 & 0.4 & 1.6 & 0.3 \\
\hline Austria & $86-10$ & 114 & Euro $^{\mathrm{a}}$ & 143.7 & 47.5 & 164.5 & 55.1 \\
\hline Belgium & $81-10$ & 206 & Euro $^{\mathrm{a}}$ & 249.5 & 72.6 & 287.1 & 79.3 \\
\hline Brazil & $94-10$ & 44 & Real & 90.3 & 25.0 & 55.8 & 13.5 \\
\hline Canada & $81-10$ & 1351 & Canadian dollar & 9.3 & 3.1 & 7.3 & 2.4 \\
\hline Chile & $90-10$ & 208 & Chilean peso & $3,813,682$ & 280.0 & 7748.5 & 0.6 \\
\hline Colombia & $95-10$ & 51 & Colombian peso & 5436.4 & 1500.0 & 2.8 & 0.8 \\
\hline Denmark & $87-10$ & 224 & Danish krone & 1609.8 & 335.0 & 248.9 & 51.2 \\
\hline Egypt & $97-10$ & 95 & Egyptian pound & 58.3 & 24.4 & 12.6 & 5.0 \\
\hline France & $81-10$ & 966 & Euro $^{\mathrm{a}}$ & 109.5 & 40.9 & 125.9 & 45.5 \\
\hline Germany & $81-10$ & 846 & Euro $^{a}$ & 134.9 & 36.5 & 152.3 & 41.4 \\
\hline Greece & $88-10$ & 279 & Euro $^{\mathrm{a}}$ & 8.5 & 4.0 & 11.0 & 4.8 \\
\hline Hong Kong & $81-10$ & 736 & Hong Kong dollar & 4.4 & 1.0 & 0.6 & 0.1 \\
\hline India & $90-10$ & 1524 & Indian rupee & 51.0 & 9.2 & 1.4 & 0.2 \\
\hline Indonesia & $91-10$ & 264 & Rupiah & 2849.2 & 850.4 & 0.7 & 0.1 \\
\hline Ireland & $86-10$ & 71 & Euro $^{a}$ & 4.3 & 2.0 & 5.1 & 2.3 \\
\hline Israel & $86-10$ & 559 & New shekel & 128.7 & 6.9 & 43.1 & 1.9 \\
\hline Italy & $81-10$ & 312 & Euro $^{\mathrm{a}}$ & 6.7 & 3.1 & 8.4 & 3.9 \\
\hline Japan & $81-10$ & 2343 & Yen & $10,720.2$ & 706.0 & 93.1 & 5.8 \\
\hline Malaysia & $86-10$ & 721 & Ringgit & 3.4 & 1.9 & 1.2 & 0.5 \\
\hline Netherlands & $81-10$ & 233 & Euro $^{\mathrm{a}}$ & 118.6 & 24.7 & 127.3 & 27.2 \\
\hline New Zealand & $99-10$ & 66 & New Zealand dollar & 2.3 & 1.4 & 1.4 & 0.8 \\
\hline Norway & $81-10$ & 180 & Norwegian krone & 166.1 & 88.5 & 24.0 & 12.7 \\
\hline Pakistan & $93-10$ & 301 & Pakistani rupee & 63.6 & 18.0 & 1.2 & 0.3 \\
\hline Peru & $92-10$ & 126 & Nuevo sol & 149.6 & 1.6 & 48.3 & 0.6 \\
\hline Philippines & $90-10$ & 209 & Philippine peso & 41.5 & 1.8 & 1.2 & 0.0 \\
\hline Portugal & $88-10$ & 116 & Euro $^{\mathrm{a}}$ & 10.2 & 6.5 & 12.4 & 7.9 \\
\hline Singapore & $83-10$ & 369 & Singapore dollar & 2.3 & 0.9 & 1.4 & 0.5 \\
\hline South Africa & $81-10$ & 463 & Rand & 22.6 & 5.0 & 5.4 & 1.0 \\
\hline South Korea & $85-10$ & 785 & Won & 21,307 & 12,450 & 22.8 & 13.7 \\
\hline Spain & $87-10$ & 170 & Euro $^{\mathrm{a}}$ & 23.9 & 13.5 & 30.2 & 16.2 \\
\hline Sweden & $82-10$ & 325 & Krona & 98.6 & 63.0 & 13.4 & 8.2 \\
\hline Switzerland & $81-10$ & 298 & Swiss franc & 1397.9 & 510.0 & 925.0 & 348.9 \\
\hline Thailand & $89-10$ & 385 & Baht & 76.6 & 22.7 & 2.7 & 0.6 \\
\hline Turkey & $92-10$ & 272 & Turkish lira $^{\mathrm{b}}$ & 16.1 & 4.2 & 123.0 & 5.2 \\
\hline United Kingdom & $81-10$ & 2023 & British pound & 3.3 & 1.2 & 5.4 & 2.0 \\
\hline United States & $81-10$ & 2816 & US dollar & 51.3 & 21.9 & 51.3 & 21.9 \\
\hline Total & $81 \sim 10$ & 21,285 & & & & 135.9 & 4.0 \\
\hline
\end{tabular}

a Local currencies before January 1999 (2001) were converted to the euro using fixed exchange rates set on December 31 , 1998 (2000 for Greece).

b Old currencies before January 2005 were converted to new currencies using fixed conversion rates.

\section{Trends in nominal stock prices}

\subsection{Time series trends of nominal stock prices}

In this subsection, we investigate the time series trends of nominal stock prices. To obtain an overall picture of the trend in nominal stock prices, we examine the median nominal stock prices of the firms in our sample during the 1981-2010 period. To eliminate the potential effect of the entry and exit of firms on the nominal stock price trend, and the potential effect of midperiod anchor changes [stocks from euro countries (Austria, Belgium, France, Germany, Greece, Ireland, Italy, Netherlands, Portugal, and Spain) and Turkey], we include only the 1657 firms that did not have mid-period anchor changes and had existed for the entire sample period. To compare the averages of nominal prices that are in different local currencies, we "normalize" all local currencies by converting them to U.S. dollars at the exchange rate on June 30, 2000.

Fig. 1 shows the time series trends of various prices. Panel A depicts the trends of the median nominal stock prices and the median total return stock prices of the sample firms. The median nominal stock price in year $t$ is the median of the "normalized" nominal stock prices of the sample firms in year $t$. The median total return stock price is the median of the adjusted "normalized" stock prices, where the adjusted stock price reflects the actual total return (growth in the value of a share held over the sample period assuming dividends are reinvested). We also present trends in the equal- and valueweighted total "normalized" index returns constructed from the total returns of the 1657 firms. Both of these indices are scaled to be one U.S. dollar as of 1981. 


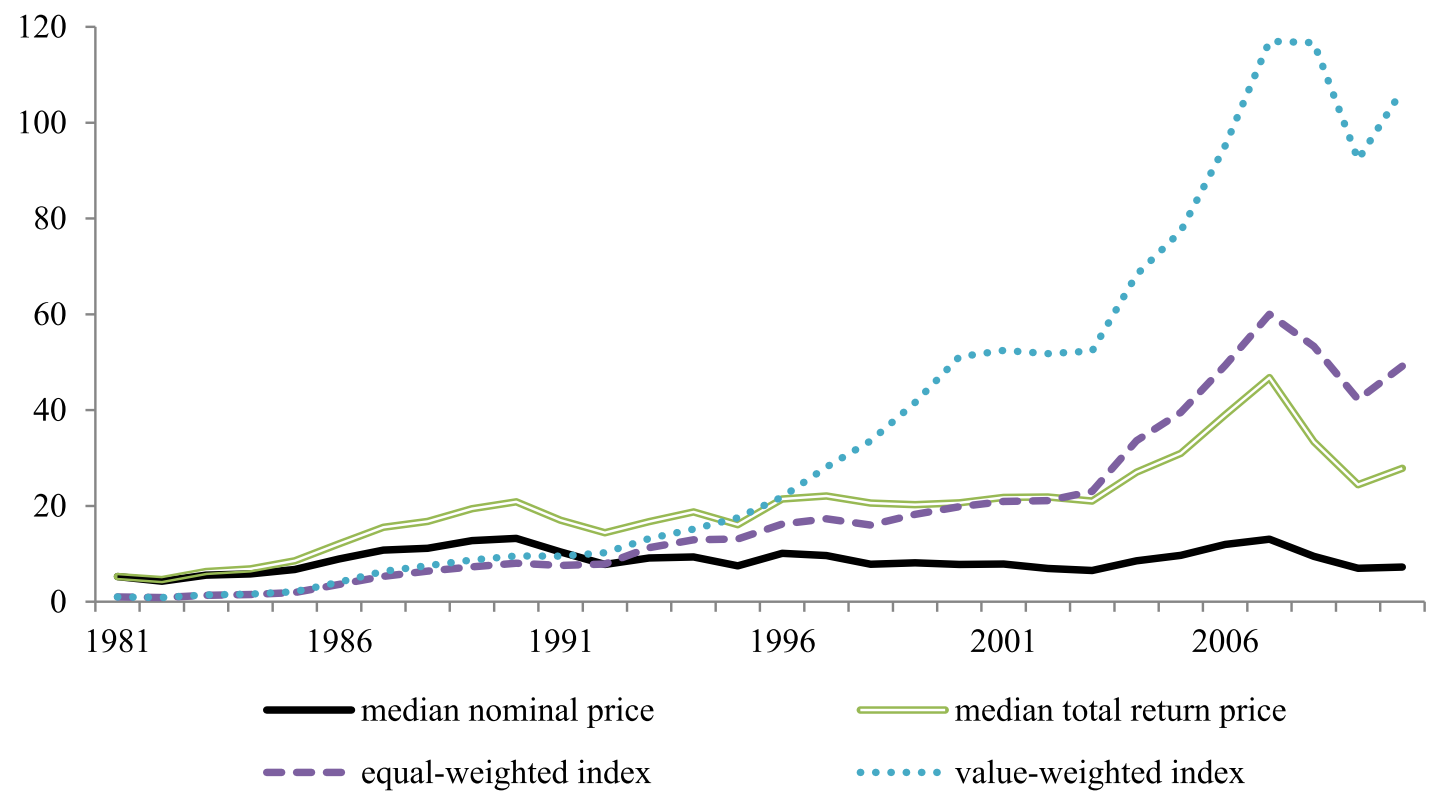

B. Median nominal stock price and inflation-adjusted total return stock price and indices

\section{US\$}

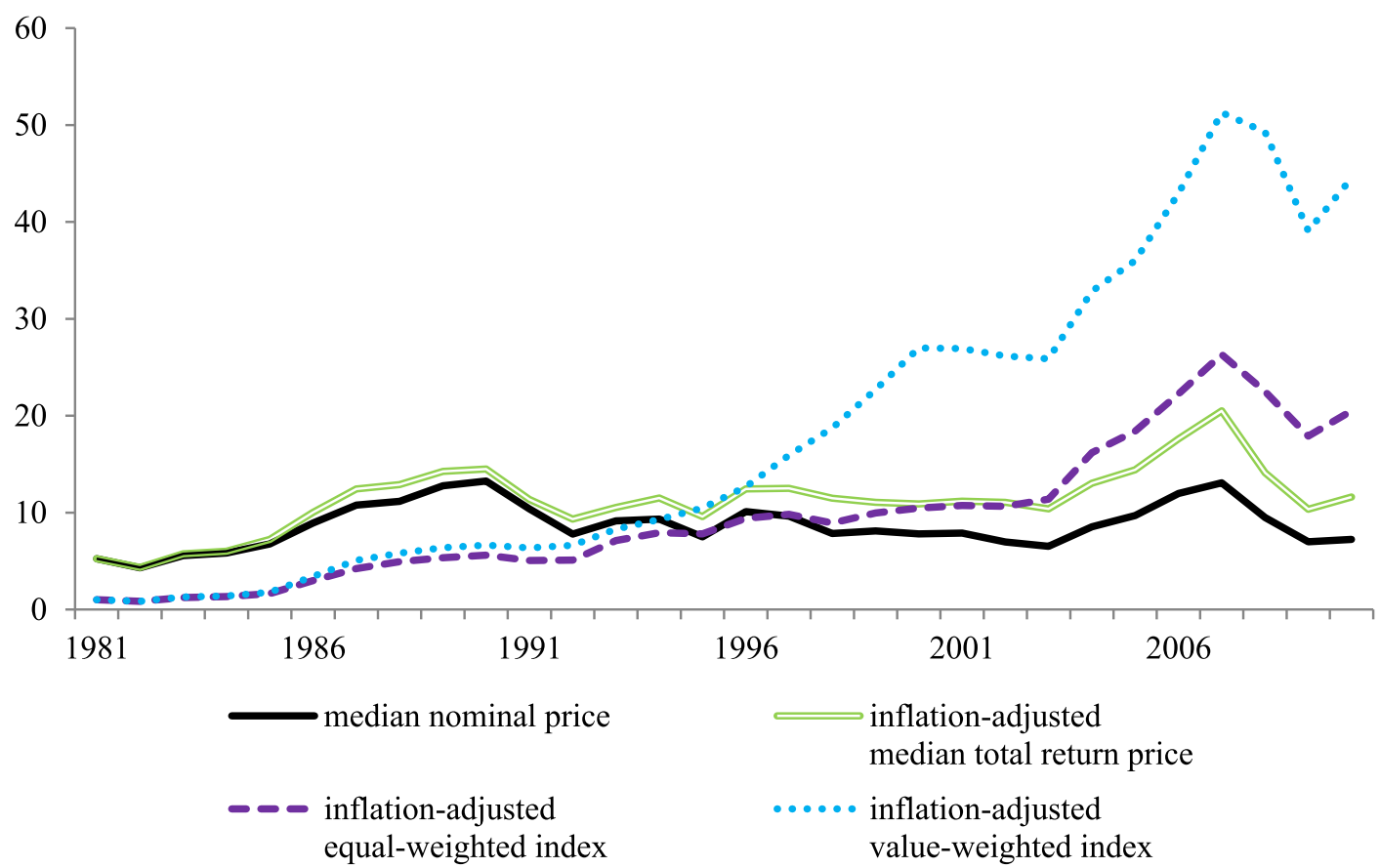

Fig. 1. Trends of median nominal stock price, median total return stock price, and equally- and value-weighted total return index. Panel A shows the trend of median nominal stock price, median total return stock price, and the equally- and value-weighted total return index for the $1981-2010$ period for 1657 firms present during the whole sample period. Euro countries (Austria, Belgium, France, Germany, Greece, Ireland, Italy, Netherlands, Portugal, and Spain) and Turkey are excluded. All local currencies are "normalized" by converting them to U.S. dollars at the exchange rate on June 30,2000 . The median nominal stock price in year $t$ is the median of the "normalized" nominal stock prices of the sample firms in year $t$. The median total return stock price is the median of the adjusted "normalized" stock prices, where the adjusted stock price reflects the actual total return (growth in the value of a share held over the sample period assuming dividends are reinvested). We also present trends in the equally- and value-weighted total "normalized" index returns constructed from total returns of the 1657 firms. Both indices are scaled to be one U.S. dollar as of 1981. Panel B shows the trend of median nominal stock price, deflated median total return stock price, deflated equally- and deflated value-weighted total return index. The last three series are deflated by the Consumer Price Index of the U.S. 
The three time series of median total return price, equal-weighted index, and value-weighted index continuously increase until 2008, suggesting that the actual total returns of the firms are positive during the sample period. However, the median nominal stock price is flat and stable throughout the sample period. This suggests that although firms generate positive returns, their nominal share prices are held roughly constant. The 2010 level of nominal stock prices is remarkably similar to the level of nominal stock prices in 1981. The time series pattern of nominal stock prices is similar to the evidence presented by Dyl and Eliott (2006) in their analyses of U.S. firms' nominal stock prices. Using 1019 firms with continuous annual price data available for the period from 1976 through 2001, they show that the average nominal price of these firms changes very little over the 26-year period when the S\&P 500 Composite Index appreciated by 1063\% and the NYSE Composite Index appreciated by $1238 \%$.

In Panel B of Fig. 1, we compare the level of the median nominal share price with the same three time series of total return indices in Panel A, adjusted for inflation. We use the U.S. Consumer Price Index as the deflator for these three time series. The figure shows that the three inflation-adjusted time series keep rising and are still above the median nominal stock price time series even after the inflation adjustment, suggesting that nominal stock prices do not keep pace with inflation. This last conclusion is the same as Weld et al. (2009).

We next investigate the phenomenon of a stable median nominal stock price at the firm level. The underlying motivation is simple. One may observe a stable median nominal price level at a global level even when no anchors exist in individual nominal prices. This is possible because upward trends of some nominal stock prices may cancel out downward trends in other nominal stock prices such that one observes no trends in the mean or the median.

\subsection{Reversion of stock prices to initial price level: tercile analysis}

In this subsection, we examine whether a firm's stock price tends to revert to its initial stock price level. For each country in each year, we partition our sample firms into tercile groups based on their nominal stock price levels. We then keep track of a firm's nominal price movement by noting the tercile groups to which it belongs year by year.

Such an analysis can tell us how many firms remain within their initial tercile group over time. If a large firm-specific shock hits a firm, whether positive or negative, its nominal stock price will likely deviate from its initial tercile group. If the firm's manager allows this deviation, the nominal stock price will leave its initial tercile group. On the contrary, if the firm's manager does not allow this deviation but "manages" the nominal share price by corporate actions, such as stock splits, stock or cash dividends, and reverse stock splits, the nominal stock price will revert to the tercile group to which it initially belonged.

Table 2 presents the results. ${ }^{6}$ The column labeled " $<50 \%$ " refers to the number of firms that stay within their initial tercile group for less than $50 \%$ of their sample years. Similarly, the columns labeled " $50 \% \leq \&<75 \%$ " and " $\geq 75 \%$ " denote the number of firms that stay within their initial tercile group, respectively, between $50 \%$ and $75 \%$, and more than $75 \%$, of their sample years.

The last row of the table shows that the nominal stock prices of 7712 sample firms stay in their initial tercile group for more than $75 \%$ of the time. These 7712 firms comprise $39.6 \%$ of the total sample of 19,465 firms. If we calculate the percentage of firms that stay in their initial tercile group more than $50 \%$ of the time, the percentage rises to $62.9 \%(=23.3 \%+39.6 \%)$. When we examine this statistic country by country, we find that the majority of firms stay in their initial tercile group more than half of the time for all countries except Indonesia, South Korea, and Thailand.

In sum, Table 2 shows that a majority of our sample firms remain in their initial nominal stock price tercile group most of the time. This finding is consistent with our conjecture that most firms seem to have anchors. However, as the results are not that strong-there is a noticeable movement across tercile groups (see Column $<50 \%$ ) we would classify these results as suggestive.

\subsection{Comparison with Weld et al. (2009)}

Weld et al. (2009) assert that nominal price fixation is primarily a U.S. or North American phenomenon. In sharp contrast, we claim that nominal price fixation is a global phenomenon. To understand why we obtain different results, we examine the nominal price patterns of the U.K. and Japan for the 1981-2010 period. Weld et al. (2009) examine 16 international stock exchanges in addition to London and Tokyo. They do not mention the other 14 countries they include in their additional analysis. They detail the nominal price movement in the U.K. and Japan, which is the reason we choose to focus on the Tokyo and London stock exchanges. Unlike Weld et al. (2009), who examine average nominal prices, we focus on median nominal prices. We believe that the pattern of median nominal price changes presents a more reliable trend than that of average nominal price changes because the nominal stock price data are highly skewed due to some outliers. Even in the U.S., adding or dropping a firm such as Berkshire Hathaway makes a huge difference in calculating nominal stock price patterns.

\footnotetext{
${ }^{6}$ In Tables 2 and 3, we exclude from our analysis observations after the introduction of the Euro (January 1999) of Euro countries (Austria, Belgium, France, Germany, Greece, Ireland, Italy, Netherlands, Portugal, and Spain) and of Turkey after its currency devaluation (January 2005). This is because old anchors get disrupted after the regime changes. In later tables, we use these anchor disruptions as a natural experiment. In Table 2, the number of firms drops to 19,465 from 21,285 in Table 1 as we drop the after-regime-change observations and again require firms to have at least 10 consecutive yearly observations before the regime change.
} 
Table 2

Percentage of firms whose stock prices in local currency remain in their initial tercile groups per country. This table presents the number and percentage of firms whose stock prices remain in their initial tercile groups for a certain percentage of the time for which they are in the sample. The nominal stock prices for each year are determined at the end of June in each year for the 1981-2010 period. Observations after the introduction of the euro (Jan. 1999) of euro countries (Austria, Belgium, France, Germany, Greece, Ireland, Italy, Netherlands, Portugal, and Spain) and after currency devaluation of Turkish lira (Jan. 2005) are excluded. To be included in the sample, firms are required to have at least 10 consecutive yearly observations. Nominal stock prices for each country in each year are partitioned by tercile groups and are assigned into a tercile group. The initial tercile group for a firm is the tercile group that it belongs to when it is initially included in the sample period. The column labeled " $<50 \%$ " refers to the number (or the percentage) of firms that stay within their initial tercile group less than $50 \%$ of their sample years. Similarly, the columns labeled " $50 \% \leq \&<75 \%$ " and " $\geq 75 \%$ " denote the number (or the percentage) of firms that stay within their initial tercile group between $50 \%$ and $75 \%$, and greater than $75 \%$, respectively, of their sample years.

\begin{tabular}{|c|c|c|c|c|c|c|c|c|}
\hline \multirow[t]{3}{*}{ Country } & \multirow[t]{3}{*}{ Period } & \multicolumn{4}{|c|}{ Number of firms } & \multirow{2}{*}{\multicolumn{3}{|c|}{ B/A (\%) }} \\
\hline & & \multirow[t]{2}{*}{ All (A) } & \multicolumn{3}{|c|}{$\begin{array}{l}\text { that remain in their initial tercile group } \\
\text { during sample period (B) }\end{array}$} & & & \\
\hline & & & $<50 \%$ & $50 \% \leq \&<75 \%$ & $\geq 75 \%$ & $<50 \%$ & $50 \% \leq \&<75 \%$ & $\geq 75 \%$ \\
\hline Argentina & $94-10$ & 80 & 33 & 22 & 25 & 41.3 & 27.5 & 31.3 \\
\hline Australia & $81-10$ & 1154 & 390 & 298 & 466 & 33.8 & 25.8 & 40.4 \\
\hline Austria & $86-98$ & 51 & 17 & 11 & 23 & 33.3 & 21.6 & 45.1 \\
\hline Belgium & $81-98$ & 110 & 32 & 18 & 60 & 29.1 & 16.4 & 54.5 \\
\hline Brazil & $94-10$ & 44 & 16 & 15 & 13 & 36.4 & 34.1 & 29.5 \\
\hline Canada & $81-10$ & 1351 & 440 & 310 & 601 & 32.6 & 22.9 & 44.5 \\
\hline Chile & $90-10$ & 208 & 44 & 28 & 136 & 21.2 & 13.5 & 65.4 \\
\hline Colombia & $95-10$ & 51 & 11 & 9 & 31 & 21.6 & 17.6 & 60.8 \\
\hline Denmark & $87-10$ & 224 & 94 & 69 & 61 & 42.0 & 30.8 & 27.2 \\
\hline Egypt & $97-10$ & 95 & 39 & 21 & 35 & 41.1 & 22.1 & 36.8 \\
\hline France & $81-98$ & 437 & 148 & 93 & 196 & 33.9 & 21.3 & 44.9 \\
\hline Germany & $81-98$ & 355 & 97 & 86 & 172 & 27.3 & 24.2 & 48.5 \\
\hline Greece & $88-98$ & 71 & 14 & 18 & 39 & 19.7 & 25.4 & 54.9 \\
\hline Hong Kong & $81-10$ & 736 & 341 & 171 & 224 & 46.3 & 23.2 & 30.4 \\
\hline India & $90-10$ & 1524 & 602 & 415 & 507 & 39.5 & 27.2 & 33.3 \\
\hline Indonesia & $91-10$ & 264 & 138 & 62 & 64 & 52.3 & 23.5 & 24.2 \\
\hline Ireland & $86-98$ & 53 & 19 & 6 & 28 & 35.8 & 11.3 & 52.8 \\
\hline Israel & $86-10$ & 559 & 202 & 118 & 239 & 36.1 & 21.1 & 42.8 \\
\hline Italy & $81-98$ & 180 & 44 & 34 & 102 & 24.4 & 18.9 & 56.7 \\
\hline Japan & $81-10$ & 2343 & 818 & 503 & 1022 & 34.9 & 21.5 & 43.6 \\
\hline Malaysia & $86-10$ & 721 & 342 & 171 & 208 & 47.4 & 23.7 & 28.8 \\
\hline Netherlands & $81-98$ & 177 & 76 & 37 & 64 & 42.9 & 20.9 & 36.2 \\
\hline New Zealand & $99-10$ & 66 & 6 & 15 & 45 & 9.1 & 22.7 & 68.2 \\
\hline Norway & $81-10$ & 180 & 66 & 47 & 67 & 36.7 & 26.1 & 37.2 \\
\hline Pakistan & $93-10$ & 301 & 91 & 62 & 148 & 30.2 & 20.6 & 49.2 \\
\hline Peru & $92-10$ & 126 & 31 & 38 & 57 & 24.6 & 30.2 & 45.2 \\
\hline Philippines & $90-10$ & 209 & 69 & 38 & 102 & 33.0 & 18.2 & 48.8 \\
\hline Portugal & $88-98$ & 69 & 18 & 19 & 32 & 26.1 & 27.5 & 46.4 \\
\hline Singapore & $83-10$ & 369 & 142 & 84 & 143 & 38.5 & 22.8 & 38.8 \\
\hline South Africa & $81-10$ & 463 & 121 & 100 & 242 & 26.1 & 21.6 & 52.3 \\
\hline South Korea & $85-10$ & 785 & 413 & 190 & 182 & 52.6 & 24.2 & 23.2 \\
\hline Spain & $87-98$ & 94 & 31 & 18 & 45 & 33.0 & 19.1 & 47.9 \\
\hline Sweden & $82-10$ & 325 & 134 & 78 & 113 & 41.2 & 24.0 & 34.8 \\
\hline Switzerland & $81-10$ & 298 & 113 & 83 & 102 & 37.9 & 27.9 & 34.2 \\
\hline Thailand & $89-10$ & 385 & 200 & 88 & 97 & 51.9 & 22.9 & 25.2 \\
\hline Turkey & $92-04$ & 168 & 82 & 31 & 55 & 48.8 & 18.5 & 32.7 \\
\hline United Kingdom & $81-10$ & 2023 & 741 & 432 & 850 & 36.6 & 21.4 & 42.0 \\
\hline United States & $81-10$ & 2816 & 999 & 701 & 1116 & 35.5 & 24.9 & 39.6 \\
\hline Total & $81 \sim 10$ & 19,465 & 7214 & 4539 & 7712 & 37.1 & 23.3 & 39.6 \\
\hline
\end{tabular}

The median nominal stock price in the U.K. in our sample is quite stable throughout the sample period and does not show any trend. It has stayed around the average of $£ 1.2$, ranging from a minimum of $£ 0.7$ to a maximum of $£ 1.7$. In Japan, the nominal stock price is more volatile and the average of the annual median prices ranges from a minimum of ¥680 to a maximum of $¥ 1460$. However, when one excludes the 1988-1991 period, the period of the stock market bubble in Japan, the median nominal share price becomes quite stable. More importantly, the median nominal stock prices in Japan show no longterm upward or downward trend whether the bubble period is included or not.

Weld et al. (2009) examine the correlation between average nominal stock prices and the primary stock exchange index for 16 international stock exchanges, and find that the New York Stock Exchange has the lowest correlation at 0.41, followed by the Toronto Stock Exchange with 0.64. They argue that the low correlations in the U.S. and Canada are suggestive of the fact that nominal price fixation is primarily a North American phenomenon. 
Table 3

Correlations of median nominal price with median total return stock price, equally- and value-weighted total return index. This table shows the correlations of median nominal price with median total return stock price, equally- and value-weighted total return index. Observations after the introduction of the Euro (Jan. 1999) of Euro countries (Austria, Belgium, France, Germany, Greece, Ireland, Italy, Netherlands, Portugal, and Spain) and after currency devaluation of Turkish lira (Jan. 2005) are excluded. The median nominal stock price in year $t$ is the median of the nominal stock prices of the sample firms in year t. The median total return stock price is the median of the adjusted stock prices, where the adjusted stock price reflects the actual total return (growth in the value of a share held over the sample period assuming dividends are reinvested). Equally- and value-weighted total return indices are constructed for each country using firms' adjusted stock prices where value-weighted is weighted by firms' market capitalizations.

\begin{tabular}{|c|c|c|c|c|}
\hline \multirow[t]{2}{*}{ Country } & \multirow[t]{2}{*}{ No. of firms } & \multicolumn{3}{|c|}{ Correlations of median nominal price with } \\
\hline & & Median total return price & Equal-weighted index & Value-weighted index \\
\hline Argentina & 80 & 0.82 & 0.71 & 0.58 \\
\hline Australia & 1154 & 0.98 & -0.48 & -0.48 \\
\hline Austria & 51 & 0.62 & 0.06 & -0.18 \\
\hline Belgium & 110 & 0.82 & 0.86 & 0.83 \\
\hline Brazil & 44 & -0.18 & -0.24 & -0.24 \\
\hline Canada & 1351 & 0.98 & -0.02 & -0.07 \\
\hline Chile & 208 & 0.91 & 0.90 & 0.89 \\
\hline Colombia & 51 & 0.86 & 0.85 & 0.87 \\
\hline Denmark & 224 & -0.15 & -0.36 & -0.54 \\
\hline Egypt & 95 & 0.42 & 0.21 & 0.09 \\
\hline France & 437 & 0.81 & -0.26 & -0.28 \\
\hline Germany & 355 & 0.58 & 0.16 & -0.08 \\
\hline Greece & 71 & 0.81 & 0.25 & 0.29 \\
\hline Hong Kong & 736 & 0.98 & -0.35 & -0.38 \\
\hline India & 1524 & 1.00 & -0.13 & -0.08 \\
\hline Indonesia & 264 & 0.84 & -0.39 & -0.36 \\
\hline Ireland & 53 & 0.85 & 0.87 & 0.85 \\
\hline Israel & 559 & 0.95 & -0.20 & -0.21 \\
\hline Italy & 180 & 0.64 & 0.41 & 0.10 \\
\hline Japan & 2343 & 0.94 & 0.51 & 0.04 \\
\hline Malaysia & 721 & 0.97 & 0.52 & -0.40 \\
\hline Netherlands & 177 & -0.29 & -0.50 & -0.46 \\
\hline New Zealand & 66 & 0.71 & 0.58 & 0.48 \\
\hline Norway & 180 & 0.54 & -0.49 & -0.48 \\
\hline Pakistan & 301 & 0.65 & 0.11 & 0.08 \\
\hline Peru & 126 & 0.63 & 0.44 & 0.42 \\
\hline Philippines & 209 & 0.94 & 0.09 & 0.06 \\
\hline Portugal & 69 & 0.86 & 0.12 & -0.29 \\
\hline Singapore & 369 & 0.94 & -0.60 & -0.64 \\
\hline South Africa & 463 & 0.90 & -0.05 & -0.08 \\
\hline South Korea & 785 & 0.32 & 0.00 & -0.15 \\
\hline Spain & 94 & 0.63 & 0.45 & 0.15 \\
\hline Sweden & 325 & 0.91 & -0.55 & -0.54 \\
\hline Switzerland & 298 & 0.26 & -0.71 & -0.77 \\
\hline Thailand & 385 & 0.92 & -0.34 & -0.39 \\
\hline Turkey & 168 & -0.31 & 0.18 & -0.14 \\
\hline United Kingdom & 2023 & 0.81 & -0.13 & -0.25 \\
\hline United States & 2816 & 0.91 & 0.77 & 0.75 \\
\hline
\end{tabular}

We follow their approach and examine the magnitude of correlations for our 38 sample countries. Table 3 shows the correlations of the median nominal price with median total return stock price, and the equally- and value-weighted total return index in 1981-2010.

The correlations of the median nominal prices for the U.S. and Canada with their respective value-weighted indices in our sample of 38 countries are 5th and 16th when ordered from the highest to the lowest correlation. The correlations of the median nominal prices for the U.S. and Canada with their respective equally-weighted indices in our sample of 38 countries are 5th and 22nd. The correlations of median nominal prices for these countries with their respective median total return share price in our sample of 38 countries are 12th and 3rd. It appears that the U.S. and Canadian correlations are not among the lowest. These countries are not outliers in this sense.

Note that our results are different from Weld et al.'s (2009) because we have a larger data set-more countries and a longer time period for non-U.S. countries - and we focus, because of outliers, on the median rather than the mean nominal price.

\section{Nominal stock price after euro introduction}

As of January 1,1999, nominal stock prices in nine EU member counties in our sample were converted to the euro using the fixed exchange rate set for each country on December 31, 1998. Table 4 reports the associated conversion rates.

We divide these nine countries into three groups. Each of these groups is given a dummy value. The dummy equals low (medium) $\{\mathrm{High}\}$ if a firm is from Ireland, Germany, or the Netherlands, whose exchange conversion rates to the euro are low 
Table 4

Euro conversion rates. The Euro was adopted on January 1, 1999 by 11 member states of the European Union. Greece became the 12th member state to adopt the Euro on January 1, 2001. This table gives the conversion rate for 9 of these 12 countries. Dummy_equals low (medium) \{High\} if a firm is from Ireland, Germany, or the Netherlands whose exchange conversion rates to euro are low (if a firm is from France, Austria or Belgium whose exchange conversion rates are medium) (if a firm is from Spain, Portugal, or Italy whose exchange conversion rates are high\}.

\begin{tabular}{lll}
\hline Currency name before conversion & Units of currency for 1 euro & Dummy \\
\hline Irish Pound & 0.78756 & Low \\
German DM & 1.95583 & Low \\
Dutch Guilder & 2.20371 & Low \\
French Franc & 6.55957 & Medium \\
Austrian Schilling & 13.7603 & Medium \\
Belgian Franc & 40.3399 & Medium \\
Spanish Peseta & 166.386 & High \\
Portuguese Escudo & 200.482 & High \\
Italian Lira & 1936.27 & High \\
\hline
\end{tabular}

Table 5

Proportion of euro firms that had stock splits. This table presents the proportion of Euro firms that conducted stock splits in $1998-2001$ by country and year. A total of 1850 euro firms that have been present during the 4-year period are selected from the nine Euro countries including Austria, Belgium, France, Germany, Ireland, Italy, Netherlands, Portugal, and Spain (excluding Greece which adopted the Euro in January 2001). The $p$-values are the result of the test of mean equality between the subperiods of $1998-1999$ and $2000-2001$. $^{* *}$, **, and * denote statistical significance at the $1 \%, 5 \%$, and $10 \%$ levels, respectively.

\begin{tabular}{|c|c|c|c|c|c|c|c|c|c|}
\hline & Ireland & Germany & Netherlands & France & Austria & Belgium & Spain & Portugal & Italy \\
\hline 1998 & 0.114 & 0.098 & 0.138 & 0.050 & 0.061 & 0.039 & 0.273 & 0.108 & 0.106 \\
\hline 1999 & 0.068 & 0.169 & 0.072 & 0.045 & 0.049 & 0.078 & 0.306 & 0.122 & 0.082 \\
\hline 2000 & 0.068 & 0.217 & 0.072 & 0.090 & 0.134 & 0.070 & 0.215 & 0.108 & 0.047 \\
\hline 2001 & 0.068 & 0.100 & 0.059 & 0.073 & 0.073 & 0.055 & 0.091 & 0.176 & 0.065 \\
\hline 1998-1999 (A) & 0.091 & 0.133 & 0.105 & 0.048 & 0.055 & 0.059 & 0.289 & 0.115 & 0.094 \\
\hline $2000-2001$ (B) & 0.068 & 0.158 & 0.066 & 0.082 & 0.104 & 0.063 & 0.153 & 0.142 & 0.056 \\
\hline$(B)-(A)$ & -0.023 & 0.025 & -0.039 & 0.034 & 0.049 & 0.004 & -0.136 & 0.027 & -0.038 \\
\hline p-value & 0.533 & 0.104 & $0.063^{*}$ & $0.000^{* * *}$ & $0.058^{*}$ & 0.853 & $0.000^{* * *}$ & 0.453 & $0.047^{* *}$ \\
\hline No. of firms & 44 & 480 & 152 & 599 & 82 & 128 & 121 & 74 & 170 \\
\hline
\end{tabular}

(if a firm is from France, Austria or Belgium, whose exchange conversion rates are medium) \{if a firm is from Spain, Portugal, or Italy, whose exchange conversion rates are high\}. These dummy values are also shown in Table 4. Note that, except for Ireland, whose conversion rate is less than 1 and so nominal prices increased, the conversion rate for the other eight countries is higher than 1, and so the nominal prices decreased for these countries. This implies that after the euro was introduced, countries like Italy had larger drops in nominal prices than countries like Germany. This external shock offers us a natural experiment to investigate what happens during the change. If stock splits (reverse stock splits) are used by firms to decrease (increase) their nominal prices towards an anchor, Italian firms should split a lot less than German firms (or perhaps even engage in more reverse-splits) after the euro introduction. We test this prediction.

While the euro came into existence on January 1, 1999, it was only in 2002 that notes and coins began to circulate. However, the euro started serving as an accounting currency in 1999, and stock prices started being discussed in euros in 1999. ${ }^{7}$ For this reason, we treat the year 1999 as the year of euro introduction. We partition the sample period into two 2-year subperiods: 1998 to 1999 before and on the year of euro introduction and 2000 to 2001 after euro introduction. A total of 1850 euro firms are present in our databases during this 4-year period in the nine euro countries.

Table 5 presents the results for stock splits. It shows the proportion of euro firms that conducted stock splits during the 1998-2001 period by country-year. After stock prices are displayed in euros on stock exchanges, we do not see a statistically significant change in the number of German firms doing stock splits after the introduction of the euro; however, the number of Italian firms doing stock splits decreases after its introduction. The statistical significance is strong, with a $p$-value of $5 \%$. More generally, there are statistically significant drops for two of the three countries (Spain and Italy) with the dummy equal to high, no statistically significant drops for any country with dummy equal to medium, and a statistically significant drop for only one country (Netherlands) with the dummy equal to low.

Table 6 presents the results for reverse stock splits. It shows the proportion of euro firms that conducted reverse stock splits during the 1998-2001 period by country-year. We see that the number of Italian firms doing reverse stock splits significantly increases after the euro introduction. The change in reverse stock splits for the other countries are insignificant.

In Table 7, we combine the results of Tables 5 and 6. It shows the results of a formal regression analysis at the firm level, where the dependent variable is the difference in $y$ from the post-euro introduction period (2000-2001) to the pre-euro 
Proportion of euro firms that had reverse stock splits. This table presents the proportion of Euro firms that conducted reverse stock splits during 1998-2001 by country and year. A total of 1850 Euro firms that have been present during the 4-year period are selected from the nine Euro countries including Austria, Belgium, France, Germany, Ireland, Italy, Netherlands, Portugal, and Spain (excluding Greece which adopted the Euro in January 2001). The p-values are the result of the test of mean equality between the subperiods of 1998-1999 and 2000-2001. ***, **, and * denote statistical significance at $1 \%$, $5 \%$, and $10 \%$ levels, respectively.

\begin{tabular}{|c|c|c|c|c|c|c|c|c|c|}
\hline & Ireland & Germany & Netherlands & France & Austria & Belgium & Spain & Portugal & Italy \\
\hline 1998 & 0.023 & 0.000 & 0.000 & 0.000 & 0.000 & 0.000 & 0.000 & 0.000 & 0.000 \\
\hline 1999 & 0.000 & 0.000 & 0.020 & 0.000 & 0.000 & 0.000 & 0.000 & 0.000 & 0.035 \\
\hline 2000 & 0.000 & 0.000 & 0.007 & 0.002 & 0.000 & 0.000 & 0.008 & 0.000 & 0.059 \\
\hline 2001 & 0.000 & 0.000 & 0.007 & 0.002 & 0.000 & 0.000 & 0.000 & 0.000 & 0.100 \\
\hline 1998-1999 (A) & 0.011 & 0.000 & 0.010 & 0.000 & 0.000 & 0.000 & 0.000 & 0.000 & 0.018 \\
\hline 2000-2001 (B) & 0.000 & 0.000 & 0.007 & 0.002 & 0.000 & 0.000 & 0.004 & 0.000 & 0.079 \\
\hline$(B)-(A)$ & -0.011 & 0.000 & -0.003 & 0.002 & 0.000 & 0.000 & 0.004 & 0.000 & 0.062 \\
\hline$p$-value & 0.322 & - & 0.565 & 0.158 & - & - & 0.319 & - & $0.000^{* * *}$ \\
\hline No. of firms & 44 & 480 & 152 & 599 & 82 & 128 & 121 & 74 & 170 \\
\hline
\end{tabular}

Table 7

Change in stock splits and reverse stock splits at firm level after the introduction of the euro. This table presents the result of a panel regression where the dependent variable is the difference in y from the post-Euro sub-period (2000-2001) to the pre-Euro sub-period (1998-1999). In columns (1) to (3), y is the number of stock splits per firm in each of the 2 year sub-periods divided by 2 ; in columns (4) to (6), y is the number of stock reverse splits per firm in each of the 2 year sub-periods divided by 2. Columns (1) and (4) use all 9 Euro sample countries; columns (2) and (5) exclude Ireland, Austria, and Portugal where the number of sample firms is less than 100; and columns (3) and (6) include only Germany and Italy. Independent variables are two dummy variables, dummy_low and dummy_high. Dummy_low (dummy_high) takes the value of 1 if a firm is from Ireland, Germany, and Netherlands whose exchange conversion rates to Euro are low (if a firm is from Spain, Portugal, and Italy whose exchange conversion rates are high), and zero otherwise. In columns ( 3 ) and (6), regressions are run without constant. $t$-statistics in parentheses are based clustered standard errors at the country level. Numbers in brackets are $p$ values for the test of equal coefficients on dummy_low and dummy_high.***,**, and * denote statistical significance at the $1 \%, 5 \%$, and $10 \%$ levels, respectively.

\begin{tabular}{|c|c|c|c|c|c|c|}
\hline \multirow[t]{2}{*}{ Variables } & \multicolumn{3}{|c|}{ Change in stock splits } & \multicolumn{3}{|c|}{ Change in reverse stock splits } \\
\hline & $(1)$ & $(2)$ & (3) & (4) & (5) & (6) \\
\hline dummy_low & $\begin{array}{l}-0.024 \\
(-1.28)\end{array}$ & $\begin{array}{l}-0.019 \\
(-1.00)\end{array}$ & $\begin{array}{l}0.025 \\
(1.63)\end{array}$ & $\begin{array}{l}-0.003^{*} \\
(-1.89)\end{array}$ & $\begin{array}{l}-0.002^{*} \\
(-2.16)\end{array}$ & $\begin{array}{l}- \\
-\end{array}$ \\
\hline dummy_high & $\begin{array}{l}-0.088^{* *} \\
(-2.53)\end{array}$ & $\begin{array}{l}-0.107^{* *} \\
(-2.87)\end{array}$ & $\begin{array}{l}-0.038^{* *} \\
(-2.00)\end{array}$ & $\begin{array}{l}0.029 \\
(1.50)\end{array}$ & $\begin{array}{l}0.036 \\
(1.68)\end{array}$ & $\begin{array}{l}0.062^{* * *} \\
(4.08)\end{array}$ \\
\hline Constant & $\begin{array}{l}0.039^{* * * *} \\
(5.55)\end{array}$ & $\begin{array}{l}0.028^{* * *} \\
(4.24)\end{array}$ & $\begin{array}{l}- \\
-\end{array}$ & $\begin{array}{l}0.001^{* *} \\
(2.94)\end{array}$ & $\begin{array}{l}0.001^{* *} \\
(3.66)\end{array}$ & $\begin{array}{l}- \\
-\end{array}$ \\
\hline F-test: dummy_low =dummy_high & [0.13] & {$[0.08]^{*}$} & {$[0.01]^{* * *}$} & {$[0.13]$} & {$[0.14]$} & - \\
\hline No. of observations & 1850 & 1650 & 650 & 1850 & 1650 & 650 \\
\hline $\mathrm{R}^{2}$ & 0.013 & 0.018 & 0.008 & 0.030 & 0.039 & 0.089 \\
\hline
\end{tabular}

introduction period (1998-1999). In columns (1) to (3), $y$ is the number of stock splits per firm in each of the two-year subperiods divided by 2; in columns (4) to (6), y is the number of stock reverse splits per firm in each of the two = year subperiods divided by 2. Columns (1) and (4) include all nine euro sample countries; in columns (2) and (5), Ireland, Austria, and Portugal are excluded where the number of sample firms is less than 100; and columns (3) and (6) include only Germany and Italy. Independent variables are two dummy variables: dummy_low and dummy_high; dummy_low (dummy_high) takes the value of 1 if a firm is from Ireland, Germany, or the Netherlands whose exchange conversion rates to the euro are low (if a firm is from Spain, Portugal, or Italy whose exchange conversion rates are high), and zero otherwise. We also run regressions without a constant as we have only Germany and Italy in the sample; the results are presented in columns (3) and (4).

The results in column (1) in Table 7 show that, if the conversion rate was $x$ local currency to 1 euro, after the adoption of the euro, the higher the $\mathrm{x}$, the larger is the drop in stock splits. We find that significant drops in stock splits exist only for countries whose nominal prices drop a lot (Spain, Portugal, and Italy). The F-test for difference of coefficients between these two groups of countries-Spain, Portugal, and Italy where nominal prices drop a lot versus Ireland, Germany, and the Netherlands where nominal prices drop much lower-is, however, not significant. The F-test results becomes significant if we drop Ireland, Austria, and Portugal where the number of sample firms is less than 100 (column (2)). The results in column (3) do not show a statistically significant change in the number of German firms doing stock splits after the introduction of the euro; however, the number of Italian firms doing stock splits decreases after the introduction. The F-test of equal coefficients strongly rejects the null hypothesis.

The results for reverse stock splits are shown in columns (4)-(6). The F-test results in column (4) show that Spain, Portugal, and Italy, where nominal prices drop a lot, have more reverse stock splits than Ireland, Germany, and the Netherlands, where nominal prices drop much lower. The findings show that reverse stock splits actually decrease for the latter group of countries. However, the F-test results are insignificant, perhaps because the sample of firms doing reverse 
stock splits is quite small. When we drop Ireland, Austria, and Portugal, where the number of sample firms is less than 100 (column (5)), we obtain similar results. The results in column (6) show a statistically significant increase in the number of Italian firms doing reverse stock splits after the euro introduction.

In summary, Table 7 provides strong evidence that firms in at least nine non-U.S. countries like to have fixed nominal anchors, and they use stock splits (reverse stock splits) to decrease (increase) their nominal prices towards an anchor.

\section{Conclusion}

In this paper, we revisit Weld et al.'s (2009) observation that the average nominal share price of NYSE and AMEX stocks has been approximately $\$ 25$ since the Great Depression and this "nominal price fixation is primarily a U.S. or North American phenomenon." Using a larger data set of nominal stock prices of individual firms from 38 countries, we find evidence that supports the existence of an anchor price in most of these countries. The nominal price fixation does not appear to be primarily a U.S. or North American phenomenon, but rather a global phenomenon. In other words, anchors are norms [a point made in Weld et al. (2009)], and norms exist in many countries.

Do firms use stock splits, which decrease nominal prices, and reverse stock splits, which increase nominal prices, to maintain nominal anchors? We find evidence for this during the introduction of the euro, where corporate actions in eurobased firms adjusted to the disappearance of old anchors and the appearance of new anchors. Specifically, firms in countries like Italy with larger drops in nominal prices after the euro introduction had fewer stock splits after the introduction. The country with the largest drop in nominal stock prices, Italy, also had higher reverse stock splits after the introduction.

We do not answer why firms anchor. It is a puzzle. We leave it to future research to explore the motivations of firms to anchor their nominal share prices.

\section{Appendix A. Supplementary data}

Supplementary data to this article can be found online at https://doi.org/10.1016/j.finmar.2018.12.006.

\section{References}

Arbel, Y., Ben-Shahar, D., Gabriel, S., 2014. Anchoring and housing choice: results of a natural policy experiment. Reg. Sci. Urban Econ. 49, 68-83.

Baker, M., Greenwood, R., Wurgler, J., 2009. Catering through nominal share prices. J. Finance 64, 2559-2590.

Baker, M., Pan, X., Wurgler, J., 2012. The effect of reference point prices on mergers and acquisitions. J. Financ. Econ. 106, 49-71.

Diamond, S., Rose, M., Murphy, B., Meixner, J., 2011. Damage anchors on real juries. Empirical Legal Stud. 8, $148-178$.

Dyl, E., Elliott, W., 2006. The share price puzzle. J. Bus. 79, 2045-2066.

Edwards, S., 1992. Exchange Rates as Nominal Anchors. National Bureau of Economic Research. Working Paper, No. 4246.

Epley, E., Gilovich, T., 2001. "Putting adjustment heuristic: differential processing of self-generated and experimenter-provided anchors. Psychol. Sci. 12 , 391-396.

Flood, R., Mussa, M., 1994. Issues Concerning Nominal Anchors for Monetary Policy. National Bureau of Economic Research. Working Paper, No. 4850.

George, T., Hwang, C.-Y., 2004. "The 52-week high and momentum investing. J. Finance 59, 2145-2176.

La Porta, R., Lopez-de-Silanes, F., Shleifer, A., 2006. What works in securities laws? J. Finance 61, 1-33.

Merton, R., 1987. A simple model of capital market equilibrium with incomplete information. J. Finance 42, $483-510$.

Schein, E., Van Maanen, J., 1990. Career Anchors. John Wiley and Sons, New York, NY.

Simonson, I., Drolet, A., 2004. "Anchoring effects on consumers' willingness-to-pay and willingness-to-accept. J. Consum. Res. 3, 681-690.

Tversky, A., Kahneman, D., 1974. Judgment under uncertainty: heuristics and biases. Science 185, 1124-1131.

Weld, W., Michaely, R., Thaler, R., Benartzi, S., 2009. The nominal share price puzzle. J. Econ. Perspect. 23, $121-142$. 